\title{
Spatial-temporal variations of water vapor content over Ethiopia: a study using GPS observations and the ECMWF model
}

\author{
Kibrom Ebuy Abraha ${ }^{1,2,4} \cdot$ Elias Lewi $^{2} \cdot$ Frédéric Masson $^{3} \cdot$ Jean-Paul Boy $^{3}$. \\ Cécile Doubre $^{3}$
}

Received: 29 January 2015/Accepted: 15 December 2015

(C) Springer-Verlag Berlin Heidelberg 2015

\begin{abstract}
We characterize the spatial-temporal variability of integrated water vapor (IWV) in Ethiopia from a network of global positioning system (GPS) stations and the European Center for Medium range Weather Forecasting (ECMWF) model. The IWV computed from the ECMWF model is integrated from the height of the GPS stations on 60 pressure levels to take both the actual earth surface and the model orography discrepancies into account. First, we compare the IWV estimated from GPS and from the model. The bias varies from site to site, and the correlation coefficients between the two datasets exceed 0.85 at different time scales. The results of this study show that the general ECMWF IWV trend is underestimation over highlands and overestimation over lowlands for wet periods, and overestimation over highlands and underestimation over lowlands for dry periods with very few exceptional stations. Second, we observe the spatial variation of the IWV. High values are obtained in those stations that are located in the north-eastern (Afar depression) sites and the south-western part of the country. This distribution is related to the spatial variability of the climate in Ethiopia. Finally, we study the seasonal cycle and inter-annual variability of IWV for all stations over Ethiopia. The main result is the strong inter-annual variability observed for the dry seasons.
\end{abstract}

Kibrom Ebuy Abraha

kibebuy@gmail.com

1 Mekelle University, Mekelle, Ethiopia

2 IGSSA, Addis Ababa University, Addis Ababa, Ethiopia

3 IPGS/EOST, Université de Strasbourg/CNRS, Strasbourg, France

4 Present Address: University of Luxembourg, Luxembourg City, Luxembourg
Keywords Ethiopia $\cdot$ Water vapor $\cdot$ GPS $\cdot$ ECMWF

\section{Introduction}

Ethiopia is located between latitude $3^{\circ} \mathrm{N}$ to $14^{\circ} \mathrm{N}$ and longitude $33^{\circ} \mathrm{E}$ to $48^{\circ} \mathrm{E}$ in East-Africa and covers an area of $1137,000 \mathrm{~km}^{2}$. It is crossed from NE (Afar Depression) to SW by the great African Rift. The topography extends from the Danakil Desert, which is located at $120 \mathrm{~m}$ below the mean sea level to the summit of Mount Ras Dashan at $4543 \mathrm{~m}$ (Fig. 1). The escarpment in the west Afar region separates the Afar Depression with a very arid climate from the high plateaus with an alpine climate. This boundary between these two regions is extremely steep $(30-40 \mathrm{~m} / \mathrm{km}$, with a maximum of about $100 \mathrm{~m} / \mathrm{km}$ ), and a resulting high lateral temperature gradient exists across the escarpment. The wide climate range in Ethiopia is related to its topography, but also to its position in the tropics and its proximity to the Indian Ocean. This is particularly the case for the distribution of rainfall in the country, which closely depends on the regional topography and on the seasonal evolution of circulation (Diro et al. 2008) and leads to significant time variations in the amount of rain. The convergence of the air masses of various regions in the Ethiopian plateau are one of the main causes of summer rains in the country (Viste and Sorteberg 2011). The main moisture source regions for Ethiopian highlands are the Indian Ocean, the Red Sea and the Congo Basin. The air drift from the Indian Ocean and from the north has the largest contribution to the release of the moisture into the northern Ethiopian highlands.

The rainfall regime in Ethiopia can be distinguished as either uni-modal or bimodal systems. Dawit (2010) classified the country into three regions based on rainfall patterns (Fig. 1). Region I includes the central and the eastern 
Fig. 1 Topography of the study area and distribution of the GPS stations in Ethiopia, Djibouti and Eritrea. The color scale (at the bottom) of the circles corresponds to the yearly averaged IWV content values for 2010. The black lines are political boundaries, and the blue lines delimit the three regions (R I, R II and R III) following the classifications by Dawit (2010) and subregions ( $R$ I-A, R I-B and R I-C) classified by this study

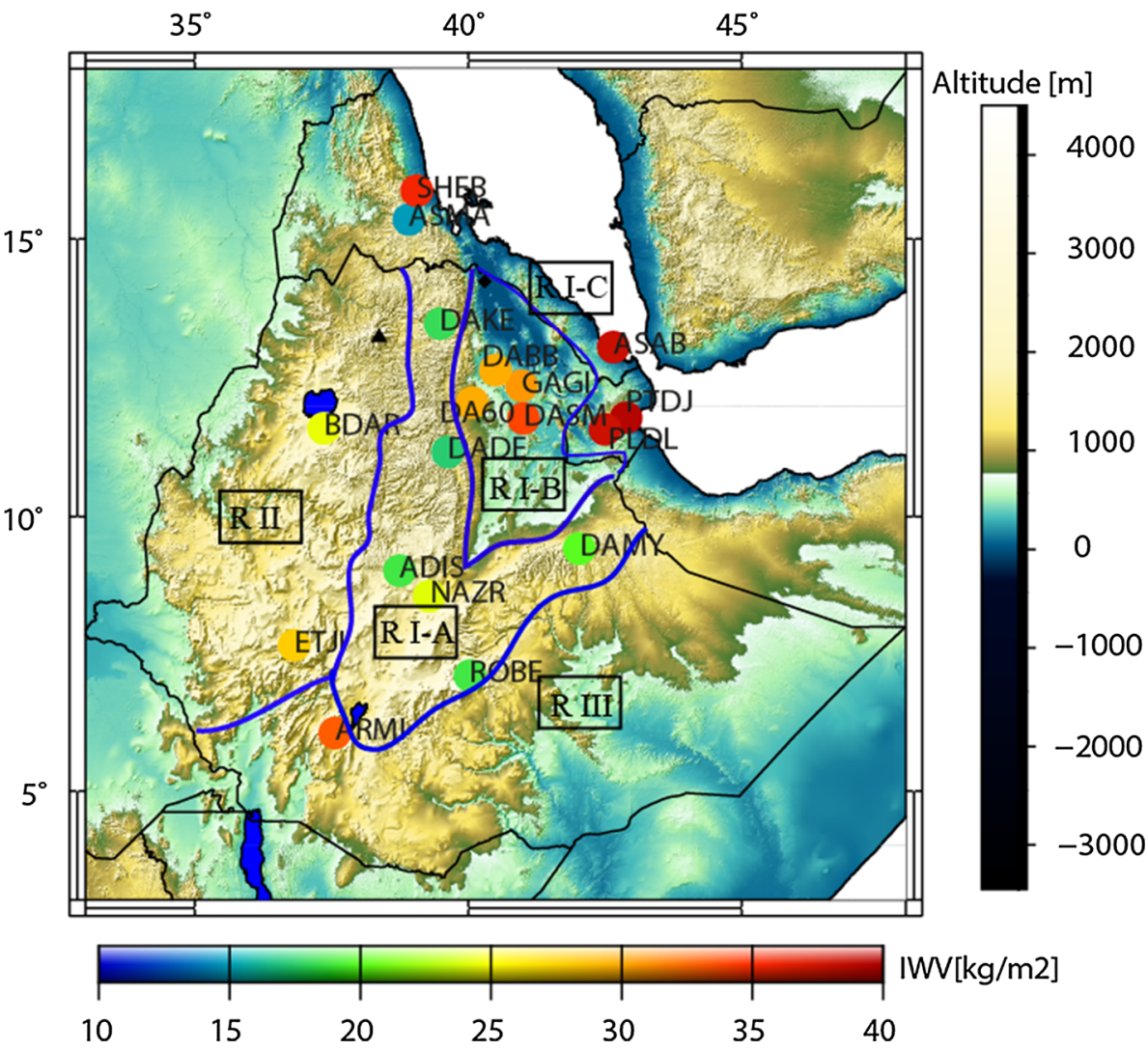

part of the country, characterized by a bimodal rain temporal pattern. In this region, the time June-September and March-May corresponds to the long and short rainy seasons, respectively. The rest of the year is dry. This region covers two different areas in terms of topography and climate: the high plateaus and the Afar Depression. Since our data allow us to discuss the spatial variations of the atmosphere content at a higher level, we chose to divide region I into three subregions: R I-A, R I-B and R I-C.

Region II covers the western part of the country from south to north, characterized by a uni-modal rainfall pattern from June to September. In addition to the main peak of rainfall, this uni-modal pattern includes a light rainy season from February through November. Region III comprises the south and south-eastern parts of Ethiopia, characterized by a bimodal rainfall pattern with two short rainy seasons, February-May and October-November, and two dry seasons, June to September and December to February.

In this study, we evaluate the spatial and temporal distribution of the water vapor in the atmosphere in Ethiopia from GPS measurements and the ECMWF model. Several methods of measurements of the distribution of water vapor have been developed by atmospheric scientists. The basis of the operational analysis and prediction system in most countries is the radiosonde (RS). Despite the good vertical resolution of these in situ measurements, RS measurements poorly resolve the temporal and spatial variability of water vapor (Bevis et al. 1992). On the contrary, ground-based GPS observations can be done at a high time and space sampling rate, but unlike RS which are inadequate in delivering a vertical humidity profile. The main advantage of GPS data is that they can be acquired continuously, with a time sampling on the order of a second. The signals deduced from other ground-based measurements, such as water vapor radiometers (WVR), can be affected by rain and clouds (Haase et al. 2003). Since we focus here on the water vapor variations in the atmosphere over Ethiopia, where no other ground-based methods exist, we use the GPS observations from continuously observing stations all over the country.

GPS methods dedicated to estimate the IWV are now well developed and commonly applied (Rocken et al. 1997; Ohtani and Naito 2000; Hagemann et al. 2003; Braun 2004). GPS analysis can be assimilated into atmospheric models (Cucurull et al. 2004, Boniface et al. 2009). Dai et al. (2002), Champollion et al. (2004) and Koulali et al. (2012) analyzed a continuous time series of GPS IWV to study its spatial-temporal variations on a multi-scale basis. Previous studies have already shown that GPS can estimate water vapor content with the same level of accuracy as other methods such as RS microwave radiometers (Elgered et al. 1991; Duan et al. 1996; Bock et al. 2008; Yan 2009). 
Inter-comparison of precipitation and IWV between GPS and ECMWF has been made for few selected stations in Ethiopia and revealed that the general circulation model has a dry bias over lowlands and a wet bias over highlands and also that the bias varies from site to site (Mengistu 2012; Mengistu et al. 2014).

Focusing on the various climates and the contrasting topography of Ethiopia, which in fact drive the climate variability over the country, we use sparsely distributed GPS stations and the ECMWF model to study the spatial and temporal variations of water vapor on a multi-scale level. The overall variability of the IWV and the relative bias between the two datasets will be discussed in light of the physical characteristics of the various regions (topography, geographical locations with respect of the sources of moistures, etc.).

\section{Data sources and processing strategies}

We present in this section the two datasets, GPS and the ECMWF model used in this study and the respective processing strategies.

\section{GPS stations distribution}

Despite the sparse distribution of the GPS stations used in this work (Fig. 1), their locations are suitable to study the water vapor content variations over various topographies and climatic areas. Stations DABB, DA60, GAGI and DASM are located in the Afar Depression area where temperature can reach $50{ }^{\circ} \mathrm{C}$ during summer, and the altitude is low (R I-B). Stations DAKE, DADE, NAZR, ADIS and DAMY are located on the plateaus, which are a few kilometers away from the stations in the Afar Depression or the East African Rift (R I-A). Stations BDAR and ETJI are located in the region II ( $\mathrm{R}$ II).

Two stations are located along the boundaries made by Dawit (2010): ROBE and ARMY (Fig. 1). After examining both the yearly rainfall pattern and the IWV variability described in the following section, we chose to attribute ROBE to region I-A. However, ARMI will not be grouped in any of the regions and will be discussed as a single station. Stations PTDJ, PLDL, ASMA, SHEB and ASAB are from neighboring countries, Eritrea and Djibouti. Since its topography and IWV variability are similar to the R I-A stations, station ASMA is grouped in this subregion. The stations PTDJ, PLDL, ASAB and SHEB are coastal sites and are attributed to region I but more specifically in a subregion R I-C.

\section{GPS data processing}

The GPS data were processed using the GAMIT (Herring et al. 2010) scientific software as described in Bock et al.
(2008). The local GPS stations in Fig. 1 are integrated with International GNSS Service (IGS) stations (ONSA, JOZE, WTZR, RAMO, IISC, NKLG, MBAR, MAL2, PRE1, MAS1) for estimating water vapor content over Ethiopia. Distant IGS stations are included in the GPS data processing in order to retrieve absolute IWV (Duan et al. 1996; Tregoning et al. 1998). The elevation cutoff angle is $10^{\circ}$ in order to increase the number of double differences for long baseline stations and to take into consideration the noise for low elevation observations.

In order to assess the accuracy of our IWV estimates, we relied on the formal zenith total delay (ZTD) errors, which are provided at the final GPS data processing stage. The day-to-day variability in the formal ZTD error at all the stations brings information on the uncorrelated behavior of the ZTD estimated values from station to station (Bock et al. 2008). In this study, the ZTD were estimated with an accuracy which is in agreement with previous studies (Haase et al. 2003; Bock et al. 2008). We followed Hagemann et al. (2003) and Bevis et al. (1992, 1994) for the equations of ZTD estimate, zenith height delay (ZHD) modeling and zenith wet delay (ZWD) conversion to IWV. The water-vapor-weighted mean temperature (Tm) values which are used to convert ZWD to IWV are calculated using the linear relationship with the surface air temperature as in Bevis et al. (1992).

\section{ECMWF model IWV retrieval}

The IWV values from ECMWF are extracted with a time resolution of $6 \mathrm{~h}$ (at $0,6,12$ and 18) from the ERA-Interim analysis archive (Dee et al. 2011). The data were extracted from a reduced Gaussian grid with a $0.7^{\circ} \times 0.7^{\circ}$ resolution (Hortal and Simmons 1991), and the IWV of the nearest grid point to the GPS station was extracted for each station without considering the effect of elevation difference between the station altitude and the altitude of the ECMWF element grid. However, because of the complex topography with large undulations in Ethiopia, this elevation difference was significant for most of the stations ( $>200 \mathrm{~m}$ for $70 \%$ of the stations used in this study, see Table 1), and the extracted IWV values of the model could not be suitable for any reliable comparison with GPS IWV values. Therefore, to overcome the bias due to the elevation difference, the IWV from the ECMWF model are integrated to the height of the GPS point. The data used in this study have a vertical resolution of 60 pressure levels with 0.1 mbar at the top level. Given 60 full levels in the model with level $p=1$ at the top and $p=60$ at the bottom, IWV is integrated from the GPS station elevation on 60 pressure levels to correct the elevation difference and then to mitigate the bias between the two datasets due to elevation differences. 
Table 1 ECMWF model IWV analysis compared to GPS IWV: the ECMWF-GPS IWV pair varies from station to station

\begin{tabular}{lrrlllllc}
\hline Station & \multicolumn{1}{c}{$\mathrm{np}$} & \multicolumn{1}{c}{ Bias } & STDV & RMS & $\mathrm{R}$ & Altitude & Orography & H diff \\
\hline PTDJ & 658 & 3.55 & 4.44 & 5.68 & 0.9 & -4.5 & 188.61 & 193.11 \\
ASAB & 1103 & 5.48 & 4.15 & 6.88 & 0.93 & 9 & 211.27 & 202.27 \\
PLDL & 643 & 5.15 & 4.08 & 6.57 & 0.92 & 101.03 & 420.1 & 319.07 \\
SHEB & 1905 & 3.01 & 4.67 & 5.55 & 0.85 & 216 & 847.03 & 631.03 \\
DASM & 671 & 3.31 & 4.2 & 5.34 & 0.9 & 418 & 532.64 & 114.64 \\
GAGI & 608 & 1.99 & 3.44 & 3.97 & 0.92 & 645.5 & 482.72 & 162.78 \\
DABB & 530 & 0.83 & 3.63 & 3.72 & 0.88 & 704.5 & 639.83 & 64.67 \\
DA60 & 939 & 0.64 & 3.4 & 3.46 & 0.9 & 836.5 & 1286.32 & 449.82 \\
ARMI & 1321 & 0.98 & 2.39 & 2.58 & 0.93 & 1200 & 1544.24 & 344.24 \\
NAZR & 1514 & -0.96 & 2.26 & 2.46 & 0.94 & 1722 & 2084.63 & 362.63 \\
BDAR & 1066 & 0.07 & 2.63 & 2.63 & 0.93 & 1793 & 2013.33 & 220.33 \\
DAMY & 969 & -2.06 & 1.75 & 2.7 & 0.96 & 2042 & 1467.1 & 574.9 \\
DAKE & 487 & -1.08 & 1.94 & 2.22 & 0.94 & 2226 & 1719.86 & 506.14 \\
ASMA & 1057 & -1.43 & 2.27 & 2.68 & 0.92 & 2321.5 & 1259.02 & 1062.48 \\
ADIS & 1221 & -2.11 & 1.72 & 2.73 & 0.95 & 2439.5 & 2239.1 & 200.4 \\
ROBE & 976 & -1.93 & 1.74 & 2.6 & 0.93 & 2458 & 2029.03 & 428.97 \\
DADE & 54 & -2.84 & 1.6 & 3.25 & 0.85 & 2580.5 & 2153.04 & 427.46 \\
\hline
\end{tabular}

Bias, STDV and RMS values are in $\mathrm{kg} / \mathrm{m}^{2}$ and altitude, orography and $\mathrm{H}$ diff are in meters

$N p$ number of ECMWF-GPS pairs, STDV standard deviation, $R M S$ root mean square, $R$ correlation coefficient, $H$ diff height difference

\section{Results}

The spatial-temporal IWV variability and the discrepancies between the two datasets as a function of topography and climatic differences will be discussed in this section.

\section{Spatial variations of IWV}

Figure 1 shows the yearly average of the IWV content for all the stations. All the values are low in region I-A (below $20 \mathrm{~kg} / \mathrm{m}^{2}$ ), while the values over all the other regions (II, I-B, III and I-C) are higher than $30 \mathrm{~kg} / \mathrm{m}^{2}$. The IWV content for stations in region I-B, i.e., within the Afar Depression, is between 30 and $34 \mathrm{~kg} / \mathrm{m}^{2}$. This relatively elevated values can be explained by the low altitude and also by the hot dry climate, which contrasts with the results from region I-A since the temperature difference between regions I-A and I-C is larger than $18{ }^{\circ} \mathrm{C}$.

The stations within the region I-C are coastal sites, which mean that the signal of high IWV content (above $36 \mathrm{~kg} / \mathrm{m}^{2}$ ) is expected to be influenced by the low elevation and the related high temperature, the humidity and the evapotranspiration cycle. The higher value of the IWV content is at the ASAB site, located on the west coast of the Red Sea, where temperatures reach about $45-50{ }^{\circ} \mathrm{C}$ during July and August. Within region II, the values are intermediate with the IWV reaching above $24 \mathrm{~kg} / \mathrm{m}^{2}$ on a yearly average. Station ARMI has high values of water vapor content, close of the values determined for regions I-C and R I-B. Several causes can explain the high value at station ARMI in the valley of the East African Rift: the proximity of planes of water, such as the Chamo and Abaya lakes and the 40 springs, the annual average temperature of $30{ }^{\circ} \mathrm{C}$, the dense vegetation and finally the extended period of rainfall even in the dry seasons.

Figure 2 shows a clear negative correlation between water vapor content and elevation for all the stations taken into account in this study. Station ARMI located at low elevation $(1200 \mathrm{~m})$ has a larger average water vapor

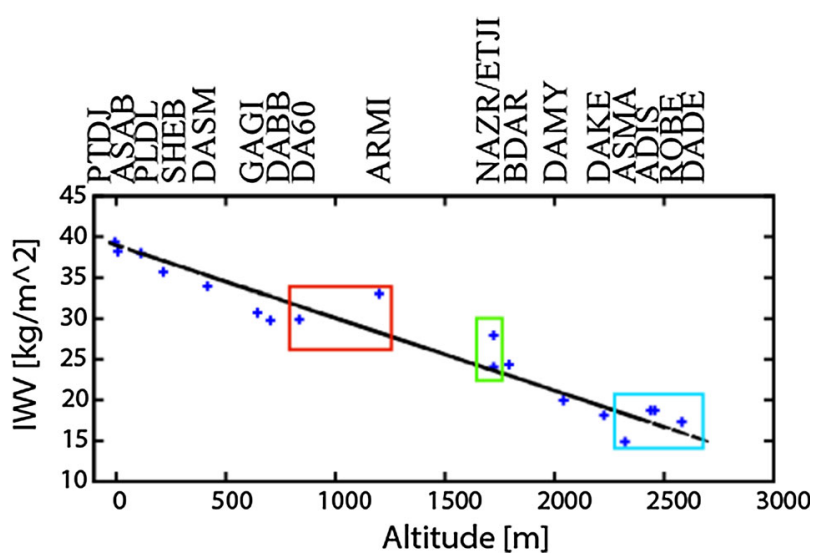

Fig. 2 Yearly averaged WV values for 2010 as a function of the station elevation. See text for details about boxed values 
content value than the regression line (red box in Fig. 2), suggesting that the IWV signal is dominated by the higher evaporation due to the presence of water, dense vegetation and higher temperature, and/or the longer period of rainfall.

The IWV value at station ETJI is large, more than about $4 \mathrm{~kg} / \mathrm{m}^{2}$ higher than NAZR which is located at a similar elevation of about $1720 \mathrm{~m}$ (green box in Fig. 2). These two stations are, however, located in distinct regions following the classification of Dawit (2010) (Fig. 1). Station ETJI is situated in a warm temperate climate, and precipitations are more evenly dispersed throughout the year.

For the stations located at elevations larger than $2000 \mathrm{~m}$ (blue box in Fig. 2), the correlation is still good, except for station ASMA, which is in the northern part of the region under study in Eritrea, near the Red Sea. ASMA shows a very low IWV with unclear reasons.

\section{Seasonal cycle and inter-annual variability}

Figure 3 shows the water vapor values for different seasons. Panel (a) shows the water vapor content for the summer season (June, July and August), panel (b) for spring (March, April and May), panel (c) for fall (September, October and November) and panel (d) for winter (December, January and February). The summer season with a high IWV content and the fall season with a low IWV content are the two extreme seasons for all regions. In general, for all regions, larger water vapor values are observed during the summer and spring (panels a and b). Larger than $25 \mathrm{~kg} / \mathrm{m}^{2}$ IWV is observed in all seasons for regions R I-B and R I-C, while for the other regions, the values go to less than $15 \mathrm{~kg} / \mathrm{m}^{2}$ for seasons of fall and winter.

Figures 4 and 5 show the time series of precipitation and IWV from GPS observations and model analyses for selected sites over the whole period under study [2007-2011] and only over the year 2008, respectively. These figures show that the IWV time series are affected by a large seasonal cycle which follows the variations of the rainfall rate at a broad scale. In more detail, we notice that periods of intense rainfalls are always associated with IWV peaks, while an IWV peak is not systematically associated with significant precipitation. According to the high complexity of the processes which are conducive to rainfall (Hally et al. 2013), this clearly confirms that rainfall is always dependent on the water vapor content and that the presence of water vapor in the atmosphere does not mean that there will always be rainfall.

Looking at the evolution over the year in Fig. 5, we are able to distinguish the bimodal rain pattern for the stations
Fig. 3 Spatial variations of IWV for four seasons: a summer (June, July and August); b spring (March, April and May); c fall (September, October and November); and d winter (December, January and February). The black lines and the blue lines refer to political and regional boundaries (see also Fig. 1)
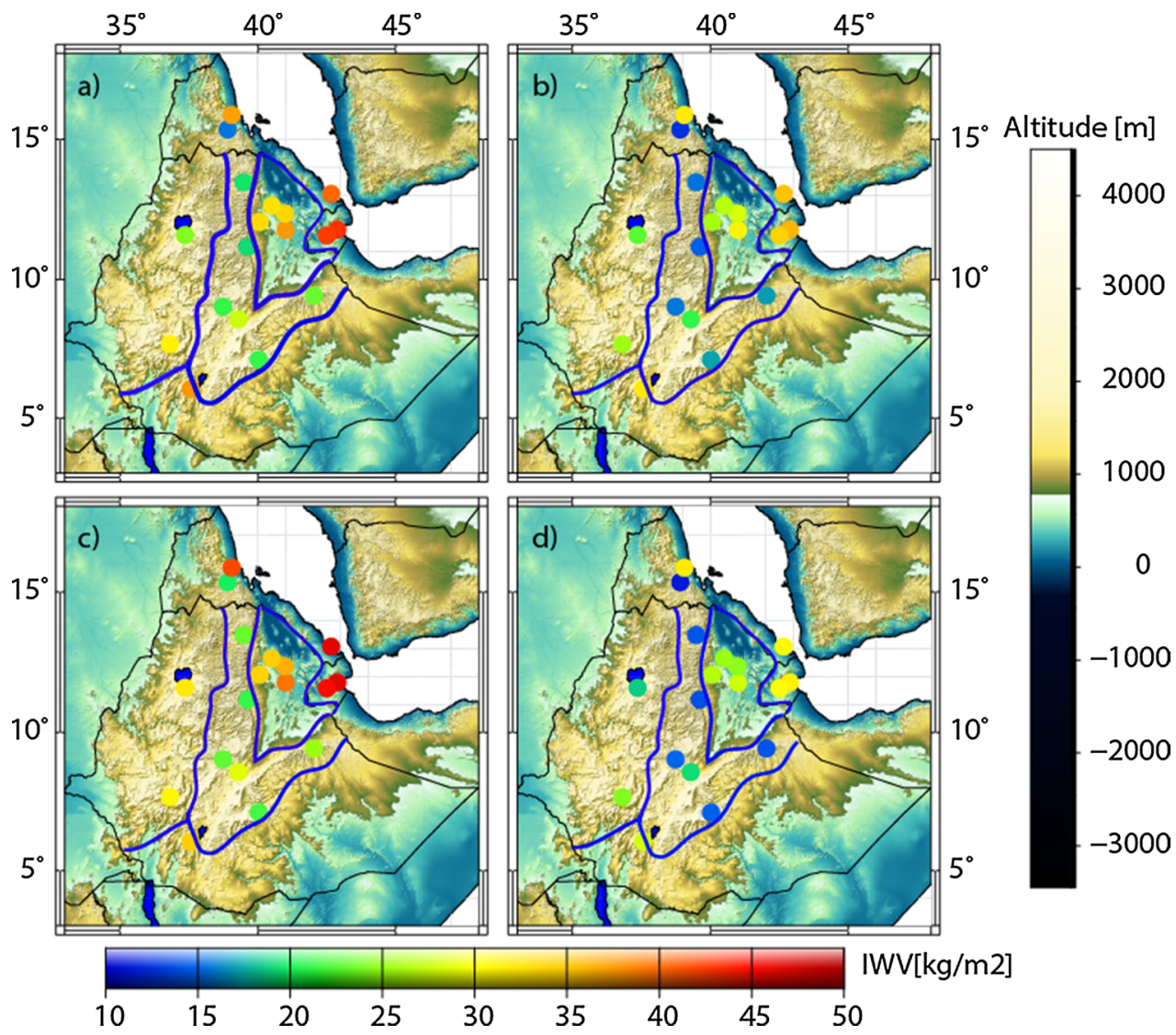

3000

2000

1000

0

$-1000$

$-2000$

$-3000$ 
Fig. 4 Time series of the IWV from ECMWF model analysis (red lines) and GPS analysis (black lines) for stations ARMI, BDAR (R II), ADIS, ROBE, DAMY (R I-A) and DASM (R I-B). Precipitation rate $(\mathrm{mm} /$ year) time series (blue bars) are from rain-gauge observations of the nearest station. Green lines show the IWV differences between GPS and ECMWF. Notice the time axis difference for $\mathbf{a}$ and $\mathbf{b}$

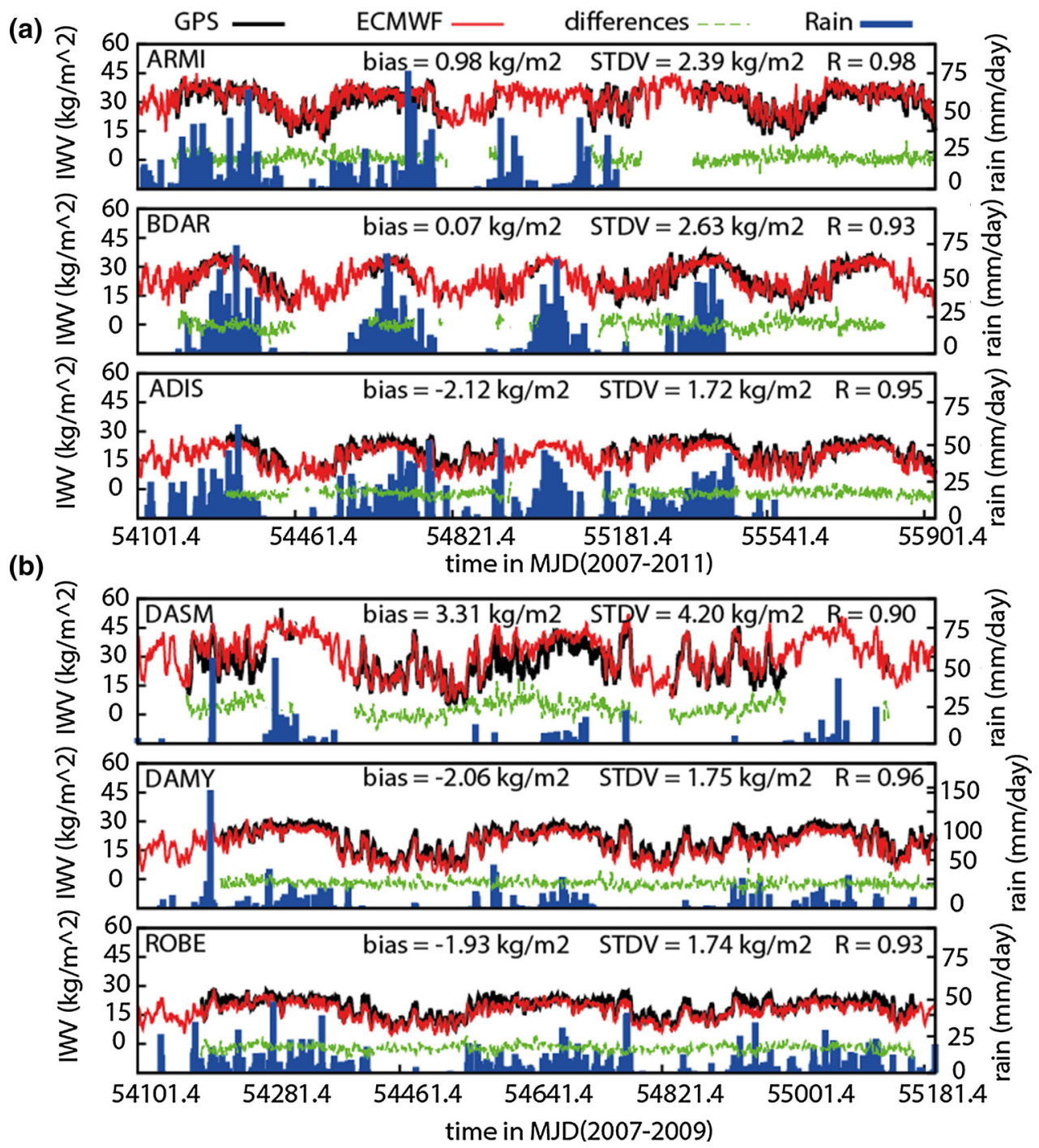

in region I-A (ADIS, DASM and DAMY); letters B1 and $\mathrm{B} 2$ indicate the long and short rainy seasons, respectively. However, we notice some rainfalls during the dry seasons such as in February and November in station ADIS. Regarding station BDAR in region II, we clearly observe the mono-modal rainfall pattern (June-September) period indicated by letter W1 in Fig. 5. The other months at this station are dry, in the sense that the content of IWV remains low, despite the fact that rainfall occurs. Stations ARMI and ROBE have bimodal rainfall patterns with two distinct dry (marked as D1 and D2) and wet (marked as W1 and W2) seasons. Relative to the other stations, the rainfalls in the region of these two stations occur for longer period over the year.

Figure 6 presents the IWV seasonal cycle and inter-annual variability from GPS and ECMWF for different regions. Following Bock et al. (2007), we define the seasonal cycle as the change in the average of IWV for each month for a period of more than 2 years (4-5 years for most of the stations) and the inter-annual variability as the standard deviation (STDV). Significant seasonal cycles are observed at all the stations, which is in fact a worldwide phenomenon. The seasonal cycle of the IWV has a bimodal pattern for regions I-B and I-C with the pattern being more visible in region I-C. Regions I-A and II show a monomodal type IWV content with the high IWV in summer season. The extended rainfall type in ARMI is the cause that the station has an extended high IWV from April to October.

For all regions, the inter-annual variability (lower parts of Fig. 6) has peaks in the dry seasons with the variability being higher for regions I-C and I-B. The reason for this might be linked to the rain events during the dry months and dry and wet air interferences (Bock et al. 2007). However, it appears that strong differences occur among the stations depending on their location in different regions. 
Fig. 5 Time series of precipitation together with IWV from ECMWF model analyses (red lines), and from GPS (black lines) for stations ARMI, BDAR (R II), ADIS, ROBE, DAMY (R I-A) and DASM (R I-B) for year 2008. Precipitation time series (blue lines) is from rain-gauge observations of nearest station. Dotted green lines show the IWV differences between GPS and ECMWF; vertical pink lines classify the different rainfall periods (see text for details)
Fig. 6 Monthly mean and standard deviation (STDV) of IWV from GPS (solid lines) and ECMWF (dotted lines) for different regions and ARMI. Both IWV values and standard deviation are in $\mathrm{kg} / \mathrm{m}^{2}$
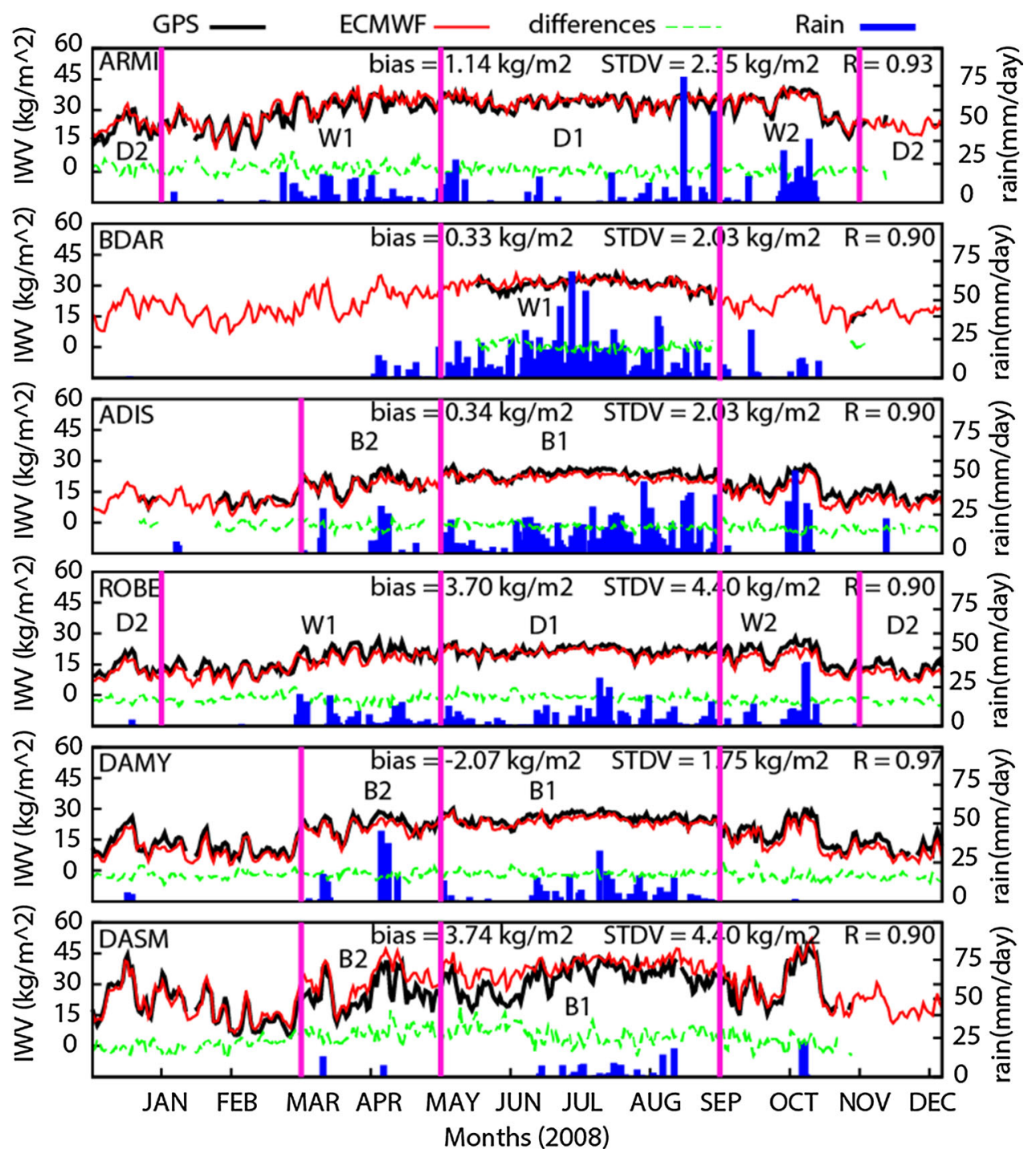
Months (2008)
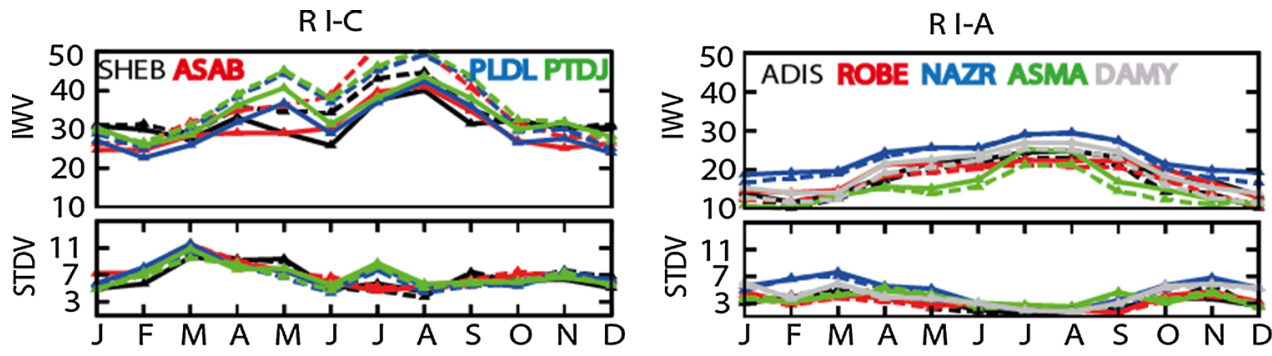

R II and ARM
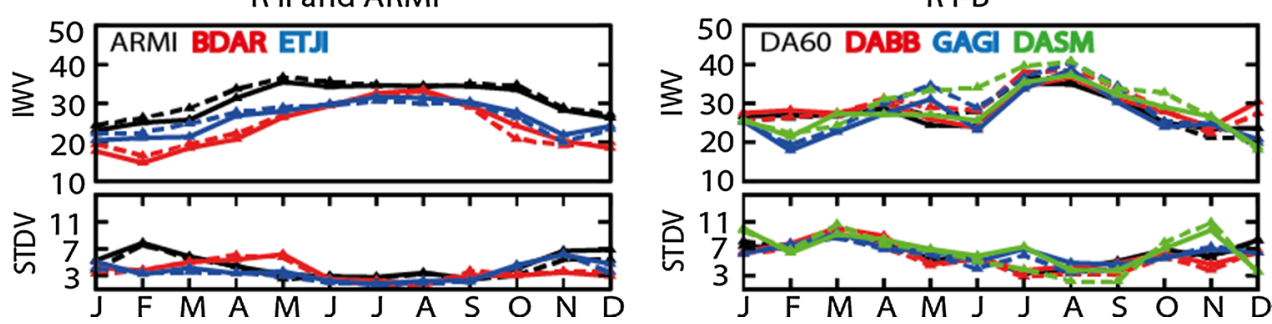
Maximum inter-annual variability $\left(11.5 \mathrm{~kg} / \mathrm{m}^{2}\right.$ according to GPS) is observed for stations in region I-C in March. As shown in Figs. 4 and 5, there are rain events for the stations even in the dry months, which play an important role in the inter-annual variability of the IWV. However, the rain pattern during the wet seasons is similar from year to year and from station to station, especially for the stations in regions I-A and II and station ARMI, and it is the reason that the inter-annual variability is small. IWV content time series at stations in the Afar Depression (region I-B) show high inter-annual variability due to the irregular rain pattern. High inter-annual variability is observed in stations from regions I-C and I-B with stations from II and I-A (stations on the high plateaus) following, and high interannual variability is observed in dry seasons.

\section{ECMWF-GPS IWV discrepancies}

Errors in the GPS derived by IWV are mainly due to errors in the estimate of the ZTD, in the computation of the ZHD from the surface pressure due to interpolation issues and in the conversion from ZWD to IWV. Errors in the ZTD are not directly related to the elevation or climate but to the GPS processing and are small. If in situ surface pressure is not available at the GPS stations, which is the case in this study, increased uncertainty arises with the interpolation of the pressure field to the GPS station (Hagemann et al. 2003). If not mentioned otherwise, GPS IWV is determined using global pressure and temperature model (GPT) surface pressure (Boehm et al. 2007) for all stations.

In order to evaluate the consistency of the IWV estimated from GPS and from ECMWF, we calculate the bias between the two sets of data for each station (Table 1). The correlation between the two datasets exceeds 0.85 at different time scales at $99.9 \%$ significance level. The bias varies from site to site. Stations from regions I-B and I-C exhibit a larger bias and STDV. The average of the difference between the STDV and RMS of the differences for all regions is about $1 \mathrm{~kg} / \mathrm{m}^{2}$ (RMS is $1 \mathrm{~kg} / \mathrm{m}^{2}$ larger than STDV), and in some stations, the difference is even larger (for ASAB, the RMS is $2.73 \mathrm{~kg} / \mathrm{m}^{2}$ larger than the STDV). This means that a systematic error must be an important contributor to the error budget, because STDV is bias free, while RMS includes systematic effects.

The sign of the bias varies from region to region and also station-wise for some sites, which is an indication of an underestimate (negative bias) and an overestimate (positive bias) of the IWV by the model. Figure 7 shows the bias and STDV between GPS and the ECMWF model for the extreme summer and fall seasons. In summer, the bias is positive over regions I-B and I-C and station ARMI, while it is negative over regions I-A and II (panel a). NAZR is an exception station in region I-A with a positive bias. In the fall, the bias is positive over regions II and ARMI. Regions I-A and I-B have a negative bias with the exception of stations DAKE and ASMA from region I-A and DASM from region I-B. Stations in region I-C exhibit a positive bias, but the bias is highly reduced relative to summer. The exceptional bias in some of the stations is linked to the fact that ECMWF captures broad features due to topographic differences but not localized characters such as vegetation and proximity to water bodies (Mengistu et al. 2014).

As Fig. 7 shows, stations from regions I-A and II and station ARMI have high STDV during summer (panel c) and low STDV during fall (panel d), while stations in regions I-B and I-C exhibit lower STDV in fall and higher STDV in summer. In summer, the STDV ranges from $2.05 \mathrm{~kg} / \mathrm{m}^{2}$ to $3.69 \mathrm{~kg} / \mathrm{m}^{2}$ in region I-B and from $3.12 \mathrm{~kg} /$ $\mathrm{m}^{2}$ to $3.62 \mathrm{~kg} / \mathrm{m}^{2}$ in region I-C, while in fall, the STDV varies from $1.92 \mathrm{~kg} / \mathrm{m}^{2}$ to $2.67 \mathrm{~kg} / \mathrm{m}^{2}$ and $1.76 \mathrm{~kg} / \mathrm{m}^{2}$ to $2.92 \mathrm{~kg} / \mathrm{m}^{2}$ for regions I-B and I-C, respectively. For regions I-A and II, the STDV varies from $1.06 \mathrm{~kg} / \mathrm{m}^{2}$ to $1.72 \mathrm{~kg} / \mathrm{m}^{2}$ and $1.83 \mathrm{~kg} / \mathrm{m}^{2}$ to $1.84 \mathrm{~kg} / \mathrm{m}^{2}$ in summer, respectively. In fall, the STDV varies from $1.31 \mathrm{~kg} / \mathrm{m}^{2}$ to $1.89 \mathrm{~kg} / \mathrm{m}^{2}$ and $2.44 \mathrm{~kg} / \mathrm{m}^{2}$ to $2.89 \mathrm{~kg} / \mathrm{m}^{2}$ for regions I-A and II, respectively. The higher STDV in summer for regions I-B and I-C and in fall for regions I-A and II and station ARMI can also be seen from the higher discrepancies between the two datasets on the specified seasons (see green dotted lines in Figs. 4 and 5). Figure 5 confirms that the discrepancies between the two datasets are similar in wet seasons for regions I-B and I-C, while the discrepancies are higher in dry seasons for regions I-A and II and station ARMI.

Over the lowlands (regions I-B and I-C), a large negative bias exists during the warm and wet summer, but over the highlands (regions I-A and II and station ARMI), the negative bias occurs in the calm and relatively dry season fall. For most of the stations, the model is in good agreement with GPS, while a varying offset indicates a dependence of errors on weather situation which is probably due to the model errors as GPS is an all-weather system. The ECMWF model suitability varies from region to region and season to season and can be the cause of the variations between the two datasets over distinct regions and seasons (Mengistu et al. 2014). If not mentioned otherwise, it should be noted that the common data pairs of ECMWF IWV and GPS IWV vary from station to station.

Mengistu (2012) showed overestimation over highlands and underestimation over lowlands for ECMWF precipitation and Mengistu et al. (2014), using fewer stations, indicated similar sensitivity to topographic differences for the ECMWF and GPS IWV with exceptional stations due to local site effects. However, the results of our study show that the general ECMWF IWV trend is underestimation 
Fig. 7 Spatial and seasonal variations of ECMWF IWVGPS IWV difference biases for two extreme seasons of summer and fall: a Bias on summer, b bias on fall, $\mathbf{c}$ STDV on summer d STDV on fall. The black lines are political boundaries, and the blue lines are the three regions (R I, R II and $\mathrm{R}$ III) which are the rain classifications by Dawit (2010) and subregions (R I-A, R I-B and $\mathrm{R} \mathrm{I-C)}$ classified by this study

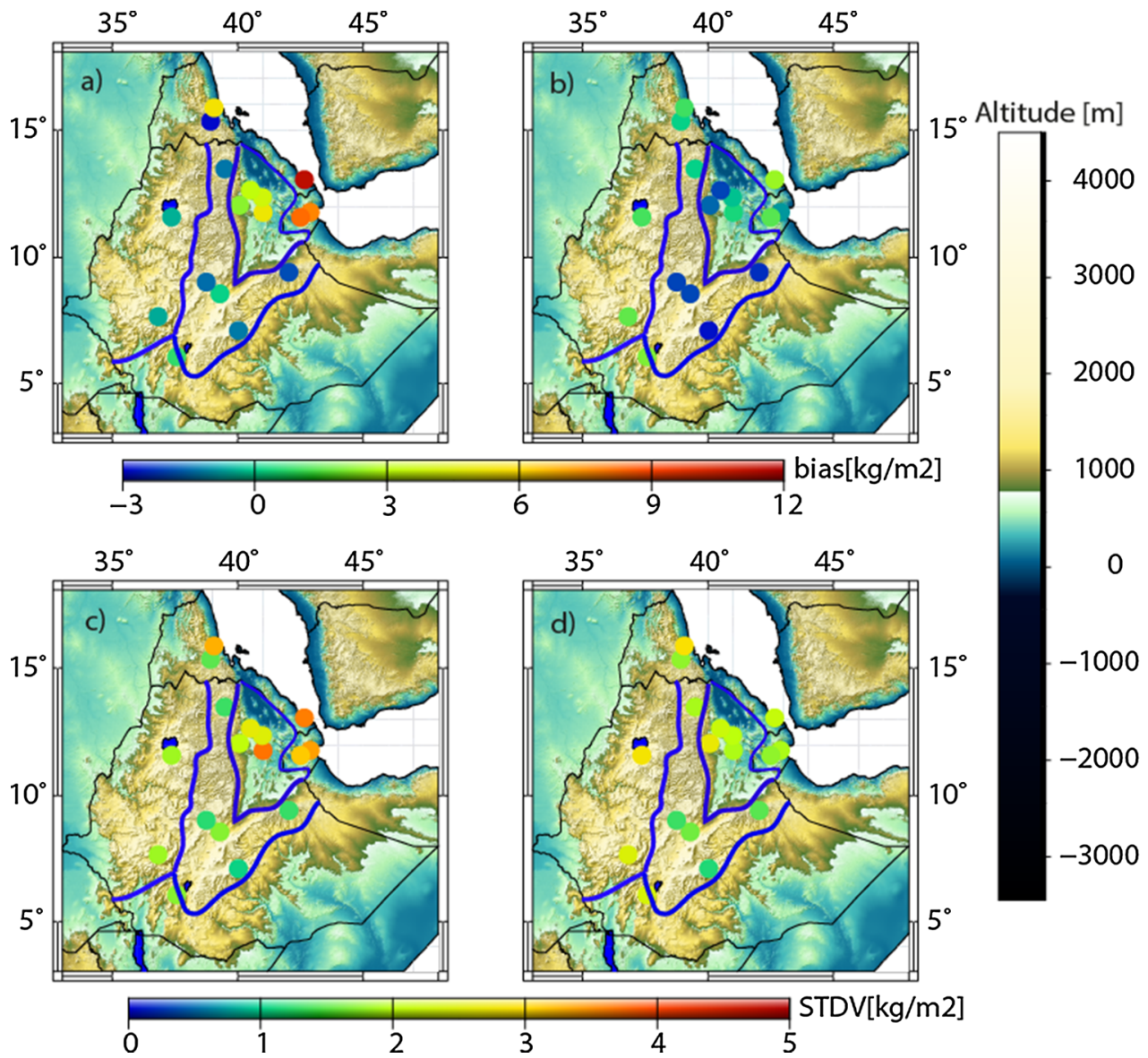

over highlands and overestimation over lowlands for wet periods and overestimation over highlands and underestimation over lowlands for dry periods, with very a few exceptional stations.

\section{Conclusions}

GPS and the ECMWF model were used to study the spatialtemporal variation of integrated water vapor content variations and the discrepancy between the two datasets over Ethiopia. The GPS IWV showed a good correlation with the ECMWF IWV values. The GPS IWV results were suitable to perceive the spatial variations of the water vapor content over Ethiopia. The correlation between the two datasets exceeds 0.85 at different time scales at a $99.9 \%$ significance level. The bias varies from region to region and site to site. In general, one observes overestimation of the ECMWF IWV over lowlands (regions I-B and I-C) and underestimation over highlands (regions I-A and II and station ARMI) for wet periods and underestimation over lowlands and overestimation over highlands for dry periods.

Because of their location in a low altitude associated with very high temperature and their proximity to large water bodies such as the Red Sea and the Indian Ocean, the coastal sites and stations from the Afar Depression exhibit larger IWV content on a yearly average which ranges between $30 \mathrm{~kg} / \mathrm{m}^{2}$ and $40 \mathrm{~kg} / \mathrm{m}^{2}$. Compared with the sites from the highlands (regions I-A and II), where the amount on a yearly average ranges from $15 \mathrm{~kg} / \mathrm{m}^{2}$ to $28 \mathrm{~kg} / \mathrm{m}^{2}$, the differences between these two extreme regions ranges from $12 \mathrm{~kg} / \mathrm{m}^{2}$ to $15 \mathrm{~kg} / \mathrm{m}^{2}$ on a yearly average. Station ARMI exhibits a high amount of IWV which reaches $33 \mathrm{~kg} / \mathrm{m}^{2}$ on a yearly average due to its proximity to dense vegetation, water bodies, its extended rainy period and its high temperature. For all regions, summer and fall are the two extreme seasons with high and low IWV values observed, respectively.

The temporal relation revealed that high values of water vapor were observed for all regions during their wet seasons. This coincides with the fact that water vapor cycles depend on seasons. Even though high integrated water vapor content is observed during high precipitation events, there are no remarkable correlations observed between rainfall and water vapor. In particular, the correlation between the two is diminished in events where pronounced integrated water vapor content is observed without any precipitation.

The inter-annual variability also differs from station to station. In terms of geography, the inter-annual variability 
is high for the stations in the Afar Depression and coastal sites. The high inter-annual variability in the Afar stations is due to the fact that the annual rainfall variability is very high. In terms of time, the inter-annual variability generally has peaks in dry seasons for all stations. Spectral analysis of the IWV from GPS shows good diurnal and semidiurnal oscillations (results not shown). The stations from the Afar Depression and coastal areas have higher diurnal and semidiurnal amplitudes than the stations from the highlands. A very high diurnal cycle was observed at stations that are located in an area where evapotranspiration is high and in areas with very high temperature.

Acknowledgments We thank all the participants of the measurement campaigns and the teams involved in making the data available. We are particularly grateful to our colleagues from the Institute of Geophysics, Space Sciences and Astronomy from the Addis Ababa University and from the Centre d'Etudes et de Recherches Djiboutiennes and the Observatoire Géophysique d'Arta (www.oga.dj). Thanks in particular to Patrice Ulrich. This work was supported by the CNES-TOSCA and by the Agence Nationale pours la Recherche, in the framework of the Project DoRA ANR-09-JCJC-0051-01.

\section{References}

Bevis M, Businger S, Herring TA, Rocken C, Anthes RA, Ware RH (1992) GPS meteorology: remote sensing of atmospheric water vapor using the global positioning system. J Geophys Res 97:15787-15801

Bevis M, Businger S, Chiswell S, Herring TA, Anthes RA, Rocken C, Ware RH (1994) GPS meteorology: mapping zenith wet delays onto precipitable water. J Appl Meteorol 33:379-386

BocK O, Guichard F, Janicot S, Lafore JP, Bouin MN (2007) Sultan B (2007) Multiscaleanalysis of precipitable water vapor over Africa from GP data and ECMWF analyses. Geophys Res Lett 34:L09705. doi:10.1029/2006GL028039

Bock O, Bouin MN, Doerflinger E, Collard P, Masson F, Meynadier R, Nahmani S, Koité MK, Balawan GL, Didé F, Ouedraogo D, Pokperlaar S, Ngamini JB, Lafore JP, Janicot S, Guichard F, Nuret M (2008) West African monsoon observed with ground-based GPS receivers during African monsoon multidisciplinary analysis (AMMA). J Geophys Res 113:D21105. doi:10.1029/2008JD010327

Boehm J, Heinkelmann R, Schuh H (2007) A global model of pressure and temperature for geodetic applications. J Geod 81:679-683. doi:10.1007/s00190-007-0135-3

Boniface K, Ducrocq V, Jaubert G, Yan X, Brousseau P, Masson F, Champollion C, Chery J, Doerflinger E (2009) Impact of highresolution data assimilation of GPS Zenith delay on mediterranean heavy rainfall forecasting. Ann Geophys 27:2739-2753

Braun JJ (2004) Remote sensing of atmospheric water vapor with the global positioning system. Dissertation, Department of Aerospace Engineering Sciences, University of Colorado

Champollion C, Masson F, Van Baelen J, Walpersdorf A, Chéry J, Doerflinger E (2004) GPS monitoring of the tropospheric water vapor distribution and variation during the 9 September 2002 torrential precipitation episode in the Cévennes (southern France). J Geophys Res 109:D24102. doi:10.1029/2004JD004897
Cucurull L, Vandenberge F, Barker D, Vilaclara E, Rius A (2004) Three dimensional variational data assimilation of ground-based GPS ZTD and meteorological observations during the 14 December 2001 storm event over the western Mediterranean sea. Monsoon Weather Rev 132(3):749-763

Dai A, Wang J, Ware RH, Van Hove T (2002) Diurnal variation in water vapor over North America and its implications for sampling errors in radiosonde humidity. J Geophys Res 107:4090. doi:10.1029/2001JD000642

Dawit A (2010) Future climate of Ethiopia from PRECIS Regional Climate Model Experimental Design. http://www.metoffice.gov.uk

Dee DP et al (2011) The ERA-Interim reanalysis: configuration and performance of the data assimilation system. Q J R Meteorol Soc 137:553-597. doi:10.1002/Qj.828

Diro GT, Toniazzo T, Shaffrey L (2008) Ethiopian rainfall in climate models. Afr Clim Clim Change 51-69

Duan J, Bevis M, Fang P, Bock Y, Chiswell S, Businger S, Rocken C, Solheim F, van Hove T, Ware R et al (1996) GPS meteorology: direct estimation of the absolute value of precipitable water. J Appl Meteorol 35(6):830-838

Elgered G, Davis JL, Herring TA, Shapiro II (1991) Geodesy by radio interferometry: water vapor radiometry for estimation of the wet delay. J Geophys Res 96(B4):6541-6555. doi:10.1029/ 90JB00834

Haase J, Ge MR, Vedel H, Calais E (2003) Accuracy and variability of GPS tropospheric delay measurements of water vapor in the western Mediterranean. J Appl Meteorol 42(11):1547-1568

Hagemann S, Bengtsson L, Gendt G (2003) On the determination of atmospheric water vapor from GPS measurements. J Geophys Res 108(D21):4678. doi:10.1029/2002JD003235

Hally A, Richard E, Fresnay S, Lambert D (2013) Ensemble simulations with perturbed physical parametrizations: preHyMeX case studies. Royal Meteorological Society

Herring TA, King RW, McClusky SC (2010) GAMIT reference manual, GPS analysis at MIT-release 10.4. Department of Earth, Atmospheric, and Planetary Science, MIT, USA

Hortal M, Simmons AJ (1991) Use of reduced Gaussian grids in spectral models. Monsoon Weather Rev 119:1057-1074

Koulali A, Ouazar D, Bock O, Fadil A (2012) Study of seasonal-scale atmospheric water cycle with ground-based GPS receivers, radiosondes and NWP models over Morocco. Atmos Res 104-105:273-291. doi:10.1016/j.atmosres.2011.11.002

Mengistu TG (2012) High-resolution monthly rainfall database for Ethiopia: homogenization, reconstruction, and gridding. J Climate 25(8422-8443):2012

Mengistu TG, Blumenstock T, Hase F (2014) Observations of precipitable water vapor over complex topography of Ethiopia from ground-based GPS, FTIR, radiosonde and ERA-Interim reanalysis. Atmos Meas Tech Discuss 7:9869-9915. www. atmos-meas-tech-discuss.net/7/9869/2014/. doi:10.5194/amtd-79869-2014

Ohtani R, Naito I (2000) Comparisons of GPS-derived precipitable water vapors with radiosonde observations in Japan. J Geophys Res 105:26917-26929

Rocken C, Van Hove T, Ware RH (1997) Near real-time GPS sensing of atmospheric water vapor. Geophys Res Lett 24:3221-3224

Tregoning P, Boers R, O'Brien D, Hendy M (1998) Accuracy of absolute precipitable water vapor estimates from GPS observations. J Geophys Res 103:28701-28710

Viste E, Sorteberg A (2011) Moisture transport into the Ethiopian highlands. Int J Climatol. doi:10.1002/joc.3409

Yan X (2009) Assimilation de données GPS pour la prévision de la convection profonde. Dissertation, Universite de Toulouse 


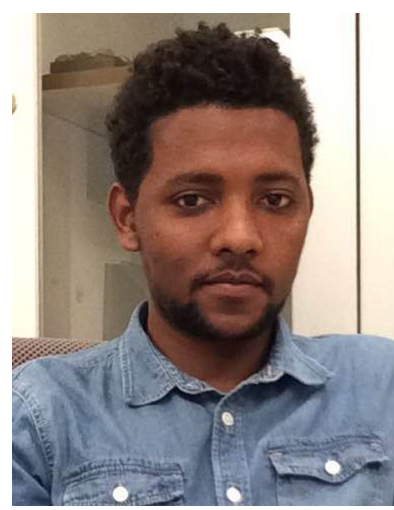

Kibrom Ebuy Abraha is a $\mathrm{Ph} . \mathrm{D}$. candidate at the University of Luxemburg. He obtained his B.S. degree (2010) in Physics from the University of Mekelle, Ethiopia, and M.Sc. degree (2013) in Geodesy from the University of Addis Ababa, Ethiopia. His current research focuses on the use of multiGNSS observations for longterm monitoring applications.

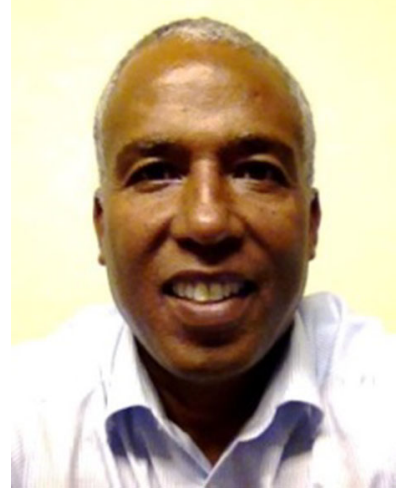

Elias Lewi is an assistant professor at the Institute of Geophysics, Space Science and Astronomy of Addis Ababa University in Ethiopia. $\mathrm{He}$ is geophysicist and geodesist in profession with the current research interest in the area of GNSS and gravimetry. He published more than 16 research papers, and he is the winner of the 2012 KAAD Stiftung Peter Hünermann award.

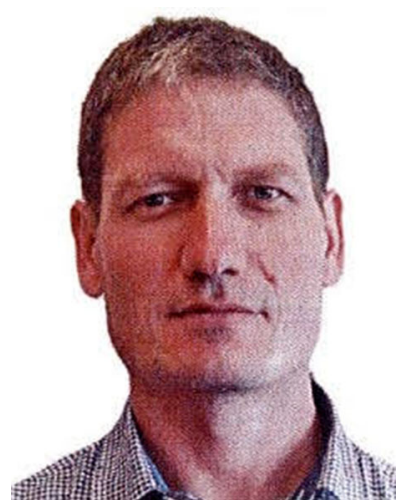

Frédéric Masson is professor of geophysics at the University of Strasbourg (EOST). His research focuses on two main themes: (1) characterization of the lithospheric deformation in different tectonic settings (continental collisions, major strikeslip faults, rifts, intracontinental slow deformations), using GPS technology and absolute gravity. (2) Quantification of tropospheric water vapor, using GPS technology.

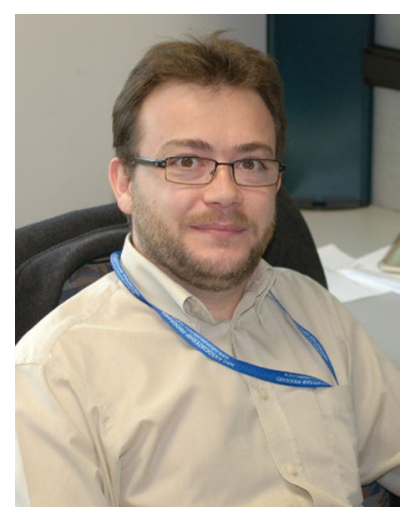

Jean-Paul Boy is associate professor at EOST/IPGS at the University of Strasbourg, specializing in gravity data analysis and processing and in modeling global earth deformation. He is currently the director of the Central Bureau of the International Geodynamics and Earth Tide Service (IGETS) and the co-chair of the Global Geophysical Fluid Center (GGFC) of IERS.

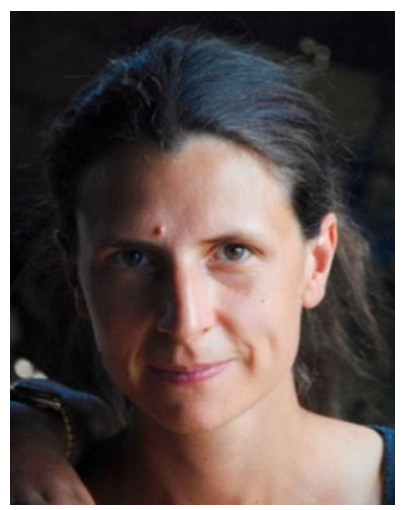

Cécile Doubre is associate professor at University of Strasbourg since 2007. Her current research mainly focuses on the quantification of the seismic and aseismic deformation associated with active rifting using InSAR, GPS and seismic data. 